\title{
Research on Size Precision of Implant Fixtures among Four Different Types of Fastening Methods
}

\author{
Soo-chul Park ${ }^{1}$, Chang-suk Kim ${ }^{2}$ and In-ho Jeong ${ }^{1, \dagger}$ \\ ${ }^{1}$ Department of Dental Technology, Gimcheon University, \\ 214 Daehakro Gimcheon City, Gyeongbuk 740-704, Korea \\ ${ }^{2}$ Department of Dental Hygiene, Ulsan College \\ 101 Bongsuro Donggu Ulsan, 682-715, Korea \\ tremedios01@naver.com
}

\begin{abstract}
This study carried out size dimensional test selecting regular size implant fixtures that have similar upper diameter and the longest implant fixtures among four different types of fastening methods processed surface with SLA. Size test result of implant fixture upper diameter of 4 kinds by each conclusion method, all test pieces showed small variation less than standard size $\pm 1 \%$, which is the norm standard size in exam specification standards of dental implant Dimensional medical devices test at the Republic of Korea Food and Drug Administration.
\end{abstract}

Keywords: Implant systems, implant surface processing, Implant Size, SLA Implant

\section{Introduction}

Thanks to development of Implanting methods, stable prosthetic dentistry methods of treating of teeth has been used without deleting of surrounding teeth, from prosthetic dentistry methods of treating by rehabilitation with crowns after erasing surrounding teeth in loss part or from prosthetic dentistry methods of temporary dentures in that defective areas are wide $[1,2,3]$.

Early dental implants were used to smooth surface implant fixtures manufactured by Machine surface but they have drawback that took too much time to install prosthesis because of requiring long term to react to bone and marrow fusion implants, therefore many researches have been studied to shorten its convergence of goal $[4,5]$. According to many precedent studies, the implant fixtures processed roughly on the surface happened to more rapid marrow fusion than those of smooth by Machine surface and also, rough surfaces resulted in precise marrow symphysis between marrow and wide contact areas of implant $[6,7,8]$. The ways to make widely and roughly on the surface are titanium Plasma jet, hydroxyapatite (HA) coating method, hydroxylapatite blasting, RBM (Resorbable Blast Media) treated implant surface processing method using fine particles powder spray surface treatment method including (Tricalcium phosphate ; TCP), SLA(Sandblasted Large - grit and Acid - etched) which is treated roughly to expand the surface areas by spin-off the primary chemical through the acid treatment after surface treatment including Hydroxylapatite powder and Tricalcium Phosphate powder spray, and various surface coating methods as to each manufacturing companies $[3,9,10]$.

All metallic materials have their own coefficient of thermal expansion and difference of thermal expansion coefficient in each pair of metals, and thermal expansion coefficient of titanium, $8.6 \times 10^{-6} /{ }^{\circ} \mathrm{C}$ with at $25^{\circ} \mathrm{C}$ is lower than those of basic metal materials[11]. If manufacturing process of implant does not maintain constant temperature, microscopic difference of precision could happen to cause by thermal expansion coefficient of 
commercially pure titanium and by volume change of cutting tool because implant product in finishing process is required precision security. Also, because of wearing of polishing tool, size of implant can grow impalpably.

In Korea, many implant products were distributed being approved by the Korea Food and Drug Administration and the Food \& Drug Administration has been managing after permission whether the products are fit in permission standard. 63 products of 251 categories of medical device products that circulate in domestic in 2011 were incongruent in quality standards, and 3of these implant products were exceeded or short of measurement by size error of notation [12].

While researches involving implanting until now were physical tests or the stability of biopsies the studies such as surface treatment states regarding symphysis $[9,10]$, shearing strength test of implant $[13,14]$, implant screw annealing associated with fastened method $[15,16,17]$, there was no study about size precision of outside about differences of fixed screen display size and actual length and diameter. The purpose of this study is to utilize by dental health data by investigating difference of indication size and actual size by carrying out size dimensional test selecting regular size implant fixtures that have similar upper diameter among four different types of fastening methods processed surface with SLA.

\section{Research Methods}

\subsection{Test Methods}

This study used four types of implant fixtures manufactured and sold in the Republic of Korea, aiming at regular size for similar upper diameter and the longest implant fixtures each tightening system bone level (Height) (Table 1). Internal Hexagon connection Implant (A\&B Implant, A\&B Biomedi, KOREA) of submerged type with morse taper of $1.5^{\circ}$ and External Hexagon connection implant (YE Implant, Yesbiotech, KOREA) of submerged type, Internal hexagon connection Implant (YS Implant, Yesbiotech, KOREA) of submerged type with $11^{\circ}$ morse taper, Internal octagon connection Implant (YI Implant, Yesbiotech, KOREA) of non-submerged type with $8^{\circ}$ morse taper, the Implant fixtures $(\mathrm{N}=5)$ of 4 different kinds of fastening methods were targeted. CCD Camera with Zoom lens, Video Meter (VMS-1510, Rational, China) that is non-contact optical measurement instrument and possible to measure by $150 \times 100(\mathrm{~mm})$, were used to the size measurement test for upper diameter of implant fixtures (Fig 1), and each specimens were measured three times and then estimated the average in order to measure as precisely as possible.

Table 1. Size of 4 Types of Implant Fixtures

\begin{tabular}{ccc}
\hline & & $(\mathrm{mm})$ \\
\hline Implant type & $\varnothing$ & length \\
\hline A\&B Implant & 3.7 & 14.5 \\
YE Implant & 4.0 & 14 \\
YS Implant & 4.0 & 15 \\
YI Implant & 4.0 & 13 \\
\hline
\end{tabular}




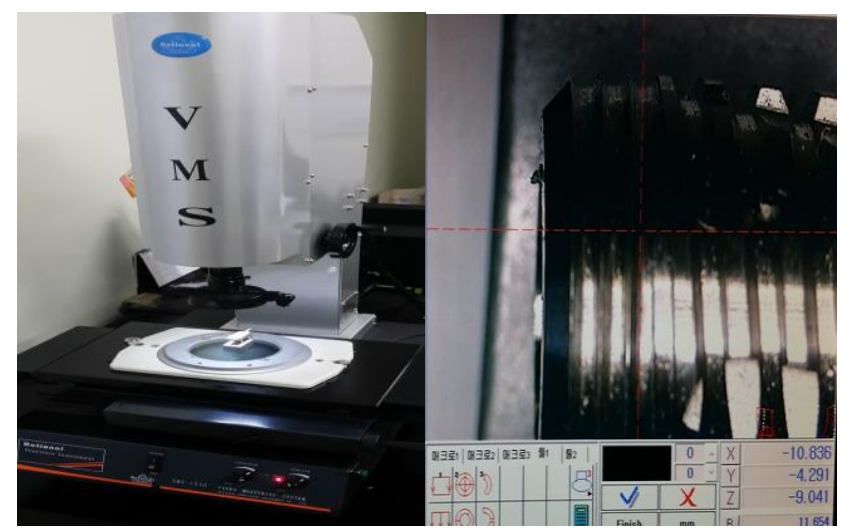

\section{Figure 1. Implant Size Test Using Non-contact Optical Measurement Instrument}

\subsection{Analysis of Test Results}

This study used a statistical program SPSS ver. 18.0 to analyze the data of upper diameter measurement of 4 types of implant fixtures, and marked measured size value and indication size (Size), average of each implant fixtures using graph. Each reference specification dimensions of the medical device implant fixtures indicated the value using a tolerance of $\pm 1 \%$, which is the norm standard size in exam specification standards of dental implant Dimensional medical devices test at the Republic of Korea Food and Drug Administration.

\section{Results}

According to the result of the upper dimension $\varnothing 3.7 \mathrm{~mm}$ test, the average of five Internal hexagon connection Implant fixtures test pieces (A\&B Implant, A\&B Biomedi, KOREA) of submerged type with $1.5^{\circ}$ morse taper is $3.7006 \mathrm{~mm}$, and the specimen No. 3 is the same $3.7 \mathrm{~mm}$ as indicated size, No. 2 is the largest as $3.703 \mathrm{~mm}$, and No.5 is the smallest as $3.698 \mathrm{~mm}$ (Fig 2).

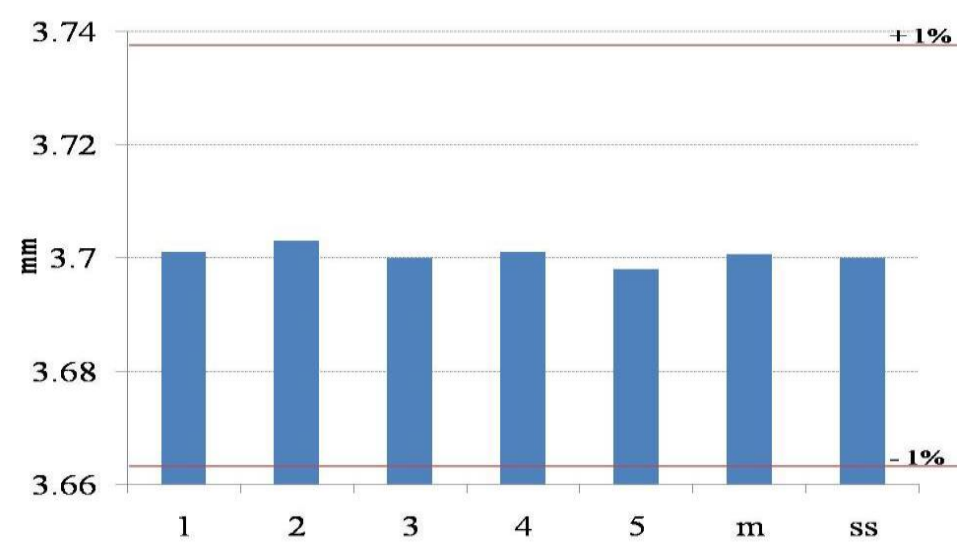

Figure 2. Upper Dimension Size Test of A\&B Implant Fixtures

$\mathrm{m}:$ mean $\pm \mathrm{SD}(3.7006 \pm 0.002 \mathrm{~mm})+0.016 \%$ ss: Standard Size. 
According to the result of the length test, the average of five Internal hexagon connection Implant fixtures test pieces (A\&B Implant, A\&B Biomedi, KOREA) of submerged type with $1.5^{\circ}$ morse taper is $14.499 \mathrm{~mm}$, and the specimen No. 1 is the same $14.5 \mathrm{~mm}$ as indicated size, No. 2 is the tallest as $14.502 \mathrm{~mm}$, and No.4 is the shortest as $14.495 \mathrm{~mm}$ (Fig 3).

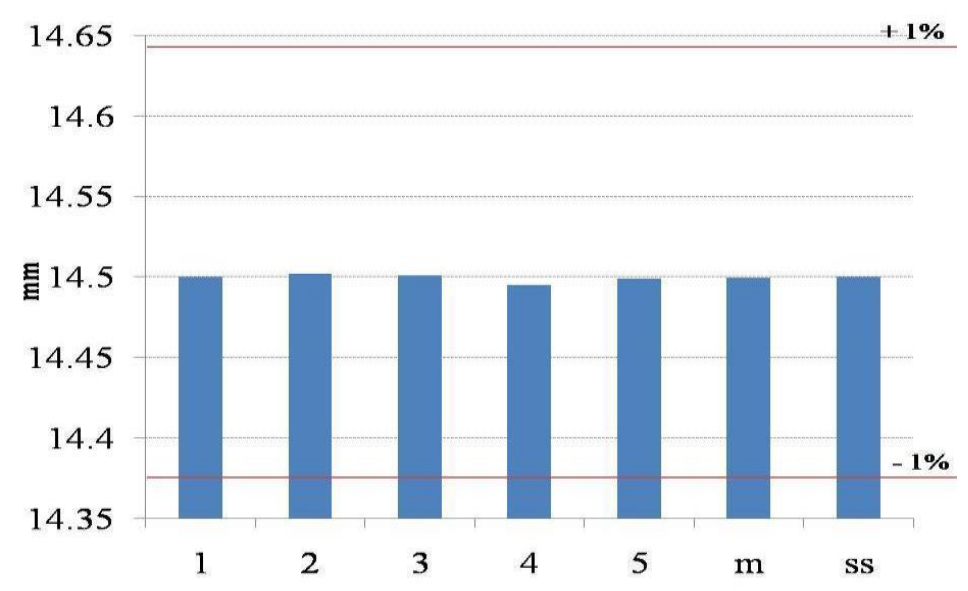

Figure 3. Length Test of A\&B Implant Fixtures

$$
\begin{aligned}
& \mathrm{m}: \text { mean } \pm \mathrm{SD}(14.499 \pm 0.003 \mathrm{~mm})-0.007 \% \text {. } \\
& \text { ss: Standard Size. }
\end{aligned}
$$

According to the result of the upper dimension $\varnothing 4.0 \mathrm{~mm}$ test, the average of five External hexagon connection Implant (YE Implant, Yesbiotech, KOREA) fixtures of submerged type is $3.998 \mathrm{~mm}$, and the specimen No. 5 is the largest by $4.002 \mathrm{~mm}$, No. 3 is the smallest by $3.989 \mathrm{~mm}$ (Fig 4$)$.

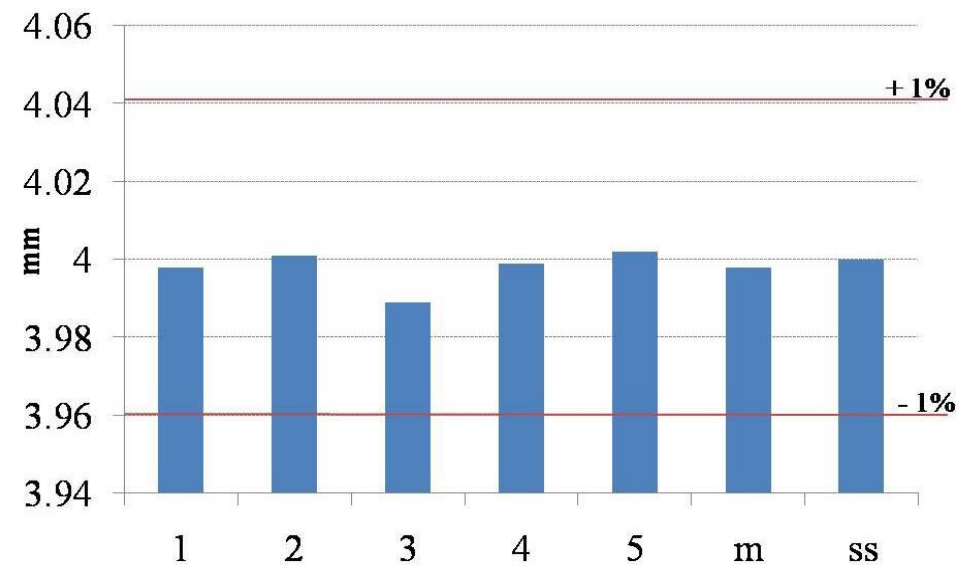

Figure 4. Upper Dimension Size Test of YE Implant Fixtures

$\mathrm{m}:$ mean $\pm \mathrm{SD}(3.998 \pm 0.005 \mathrm{~mm})+0.05 \%$.

ss: Standard Size.

According to the result of the indication size length $14 \mathrm{~mm}$ test, the average length of five External hexagon connection Implant fixtures test pieces (YE Implant, Yesbiotech , KOREA) of submerged type is $14.018 \mathrm{~mm}$, and the specimen No. 5 is the tallest as $14.034 \mathrm{~mm}$, and No. 3 is the shortest as $14.008 \mathrm{~mm}$ (Fig 5). 


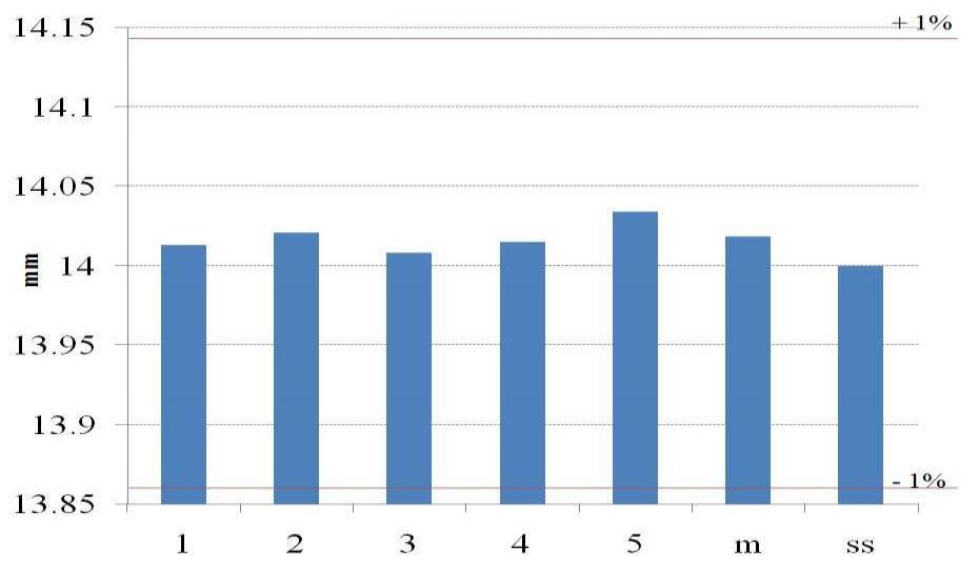

Figure 5. Length Test of YE Implant Fixtures

$\mathrm{m}:$ mean $\pm \mathrm{SD}(14.018 \pm 0.01 \mathrm{~mm})+0.129 \%$. ss: Standard Size.

According to the result of the upper dimension $\varnothing 4.0 \mathrm{~mm}$ test, the average of five Internal hexagon connection Implant fixtures test pieces (YS Implant, Yesbiotech, KOREA) of submerged type with $11^{\circ}$ morse taper is $3.994 \mathrm{~mm}$, and the specimen No. 3 is the same $4.0 \mathrm{~mm}$ as indicated size, No. 1 is the largest as $4.01 \mathrm{~mm}$, and No. 2 is the smallest as $3.98 \mathrm{~mm}$ (Fig 6).

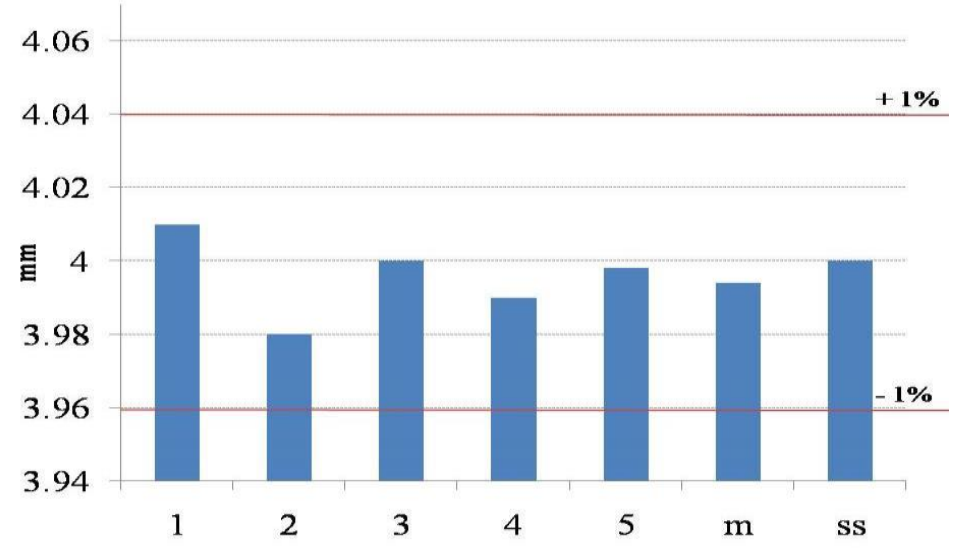

Figure 6. Upper Dimension Size Test of YS Implant Fixtures

$\mathrm{m}:$ mean $\pm \mathrm{SD}(3.994 \pm 0.114 \mathrm{~mm})-0.15 \%$. ss: Standard Size.

According to the result of the indication size length $15 \mathrm{~mm}$ test, the average length of five Internal hexagon connection Implant fixtures test pieces (YE Implant, Yesbiotech , KOREA) of submerged type with $11^{\circ}$ morse taper is $15.047 \mathrm{~mm}$, and the specimen No. 3 is the tallest as $15.07 \mathrm{~mm}$, and No. 5 is the shortest as $14.992 \mathrm{~mm}$ (Fig 7). 


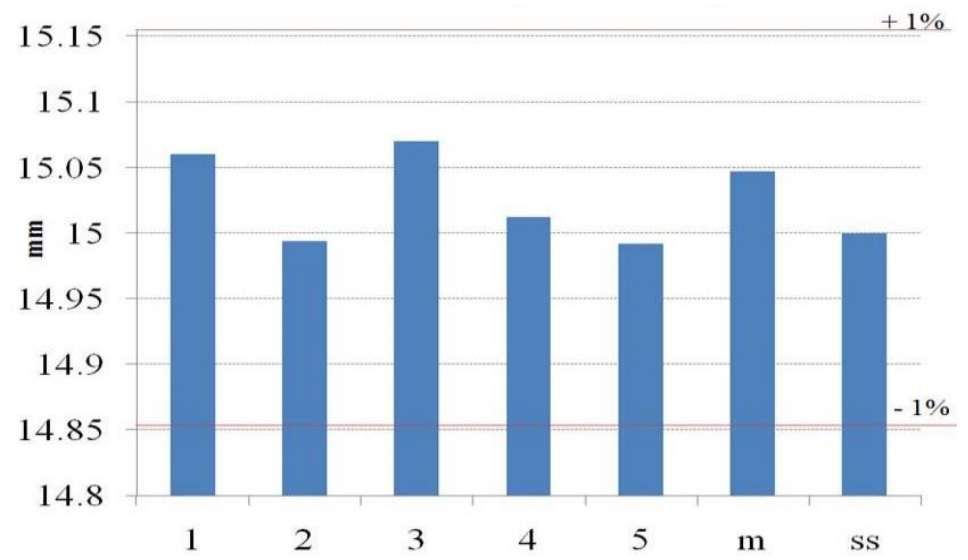

Figure 7. Length Test of YS Implant Fixtures

$\mathrm{m}:$ mean $\pm \mathrm{SD}(15.047 \pm 0.055 \mathrm{~mm})+0.313 \%$. ss: Standard Size.

According to the result of the upper dimension $\varnothing 4.0 \mathrm{~mm}$ test, the average of five Internal octagon connection Implant fixtures test pieces (YS Implant, Yesbiotech, KOREA) of Non-submerged type with $8^{\circ}$ morse taper is $4.003 \mathrm{~mm}$, and the specimen No. 5 is the same $4.0 \mathrm{~mm}$ as indicated size, No. 3 is the largest as $4.005 \mathrm{~mm}$ (Fig 8).

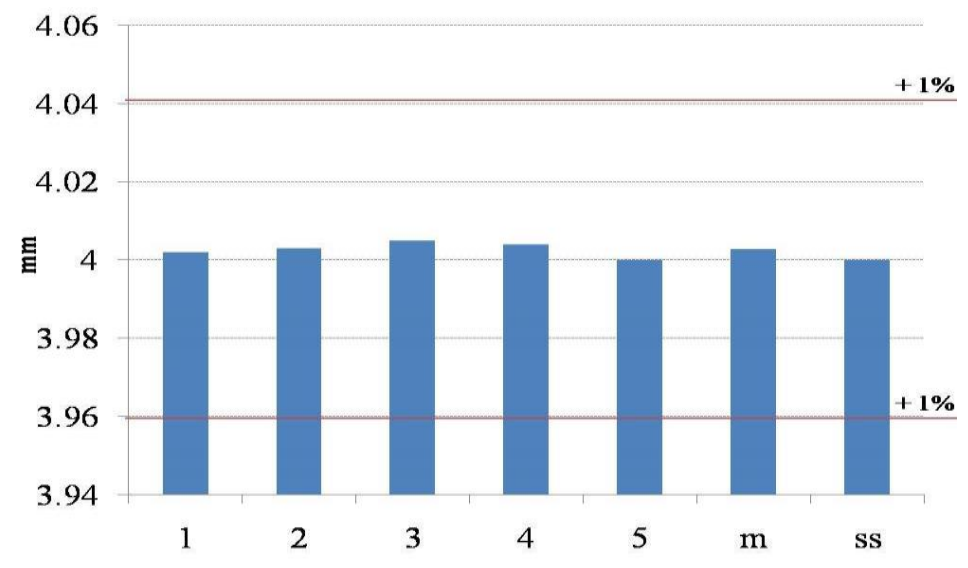

Figure 8. Upper Dimension Size Test of YI Implant Fixtures

$\mathrm{m}:$ mean $\pm \mathrm{SD}(4.003 \pm 0.019 \mathrm{~mm})+0.075 \%$. ss: Standard Size.

According to the result of the indication size length $13 \mathrm{~mm}$ test, the average length of five Internal octagon connection Implant fixtures test pieces (YI Implant, Yesbiotech , KOREA) of submerged type with $8^{\circ}$ morse taper is $13.004 \mathrm{~mm}$, and the specimen No. 5 is the same $13 \mathrm{~mm}$ as indicated size, No. 2 is the tallest as $13.01 \mathrm{~mm}$ (Fig 9). 


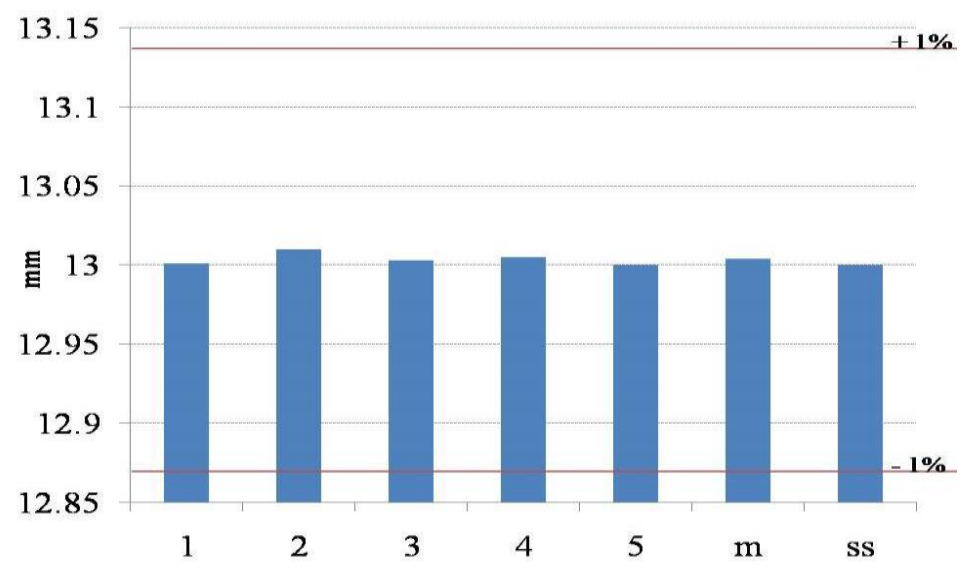

Fig 9. Length Test of YI Implant Fixtures YI

$\mathrm{m}:$ mean $\pm \mathrm{SD}(13.004 \pm 0.004 \mathrm{~mm})+0.03 \%$. ss: Standard Size.

\section{Discussion}

Implant is required enough strength and precision as well as bio compatibilities like other living body medical treatment material, and must be stability enough in a lot of occlusal loads and external force, bacterial invasion. Until now, the studies regarding precision were limited in research about precision of tightening parts of the attention of the implant fixtures and abutment posts [18], and precision of implant upper prosthetic dentistry [19]. Nowadays, the demands of prosthetic dentistry that use implant are increasing all over the world. Exterior dimension of implant has to be determined during implant surgical operation plan, implant fixtures have to be planted precisely because implant fixture with unappropriated dimension and length causes to happen to error occurrence cause of position due to not implanting on Alveolar bone boundaries exactly.

In 2011, Korea Food \& Drug Administration reported that MegaGen Implant and NeoBiotech Implant, EBi Implant, which were on domestic negotiation in 2010, were exceeded or shortened the standard [12]. There was no study about size precision of outside about differences of fixed screen display size and actual length and diameter, though there were some researches for exterior diameter but there was limit of few specimens [20].

This study got following sequence through carrying out size dimensional test selecting regular size implant fixtures that had similar upper diameter among four different types of fastening methods and was processed SLA surface.

According to the test measurement result, of the total of 20 specimens, the implants with the same indicated size and actual size are the specimen No. 3 of A\&B Implant fixtures as dimension by $\varnothing 3.7 \mathrm{~mm}$, No. 1 as length by $14.5 \mathrm{~mm}$, the specimen No. 3 of YS Implant fixtures as dimension by $\varnothing 4.0 \mathrm{~mm}$, the specimen No. 5 of YI Implant fixtures as dimension by $\varnothing 4.0 \mathrm{~mm}$, and as length by $14.5 \mathrm{~mm}$.

Volume change of polishing tools and thermal expansion coefficient of commercially pure titanium by changing in manufacture facilities [11], abrasion in the process of dealing with wears a program of equipment, replacement of various cutting tool that can occur according to common difference grant of wear occurrence, program input of implant CNC processing equipment can cause to different fixture length.

The difference indicated size and actual size is caused by increasing the length of implant fixtures of abrasive tools by wearing and tearing on the implant cutting tool of manufacturing process and decreasing length of implant fixtures of sand blasting. For indication size provision average error of $\mathrm{A} \& \mathrm{~B}$ Implant fixtures diameter by $+0.016 \%$, 
length by $-0.007 \%$, indication size contrast average error of YE Implant fixtures diameter by $+0.05 \%$, length by $+0.129 \%$, indication size contrast average error of YI Implant fixtures diameter by $+0.075 \%$, length by $+0.03 \%$. All test pieces showed small variation less than standard size $\pm 1 \%$, which is the norm standard size in exam specification standards of dental implant Dimensional medical devices test at the Republic of Korea Food and Drug Administration.

This study showed limitation to determine the differences in size by processing of production targeting the implant fixtures approved by The Food \& Drug Administration Medical instrument permission and sold on the market. Hereafter, it is necessary to research on precision by upper diameter of Implant fixtures including that it measures size using implant $\mathrm{CNC}$ processing equipment and changes from sand blasting surface process, changes from acid treatment.

\section{Conclusions}

This study got following sequence through carrying out size dimensional test using the non-contact optical measurement instrument selecting regular size implant fixtures that have similar upper diameter among four different types of fastening methods.

In diameter size test of each implant, the average of YE Implant is $3.998 \mathrm{~mm}$, that of YI Implant is $4.003 \mathrm{~mm}$, YS Implant is $3.994 \mathrm{~mm}$, and A\&B Implant is $3.7006 \mathrm{~mm}$, which were near in notation size, all of upper dimension size accuracy of four types of implant fixtures are appropriate to the reference specification for dental implant device FDA standard size $\pm 1 \%$ by the Food \& Drug Administration reference standard.

In length size test of each implant, the average of A\&B Implant is $14.499 \mathrm{~mm}$, YI Implant is $13.004 \mathrm{~mm}$, YE Implant is $14.018 \mathrm{~mm}$, and that of YS Implant is $15.047 \mathrm{~mm}$, which were near in notation size, and all of upper dimension size accuracy of four types of implant fixtures are appropriate to the reference specification for dental implant device FDA standard size $\pm 1 \%$ by the Food \& Drug Administration reference standard.

According to this study, the difference of notation size and measurement size estimates that it is caused by various factors such as worn status of polishing tools, microscopic contraction inflation by heat expansion coefficient of titanium materials by change of indoor temperature, fine polishing that is used when processing surface treatment.

Size precision of implant fixtures that is used in this research is judged to be excellent, however, implant manufacturer's production management must be controlled through systematic product management, and persistent development will have to be achieved by providing information sustainably to patients and dental workforce.

\section{Acknowledgements}

This work was supported by the Gimcheon University Research Grant.

\section{References}

[1] D. Buser, R. M. Stern, J. P. Bernard, A. Behneke, N. Behneke, H. P. Hirt, U. C. Belser and N. P. Lang, "Long-term evaluation of non-submerged ITI implants. Part 1: 8-year life table analysis of a prospective multi-center study with 2359 implants", Clinical Oral Implants Res., vol. 8, no 8, (1997), pp. 161-171.

[2] O. Bahat, "Brånemark system implants in the posterior maxilla: clinical study of 660 implants followed for 5 to 12 years", Int J Oral Maxillofac Implants, vol. 15, no. 5, (2000), pp. 646-653.

[3] R. J. Blanes, J. P. Bernard, Z. M. Blanes and U. C. Belser, "A 10-year prospective study of ITI dental implants placed in the posterior region, II: Influence of the crown-to-implant ratio and different prosthetic treatment modalities on crestal bone loss", Clin Oral Implants Res, vol. 18, no. 6, (2007), pp. 707-714.

[4] O. S. Kwon, D. H. Won, M. H. Lee, T. S. Bae and O. Y. Lee, "Effects of Electrolyte Solution on Surface Properties of Anodized Ti-6Al-7Nb Alloy", Biomaterials Research, vol. 8, no. 4, (2004), pp. 228-234. 
[5] H. Ishizawa and M. Ogino, "Characterization of thin hydroxyapatite layers formed on anodic titanium oxide films containing Ca and P by hydrothermal treatment", Journal of Biomedical Materials Research, vol. 29, no. 9, (1995), pp. 1071-1079.

[6] D. L. Cochran, “A Comparison of Endosseous Dental Implant Surfaces”, Journal of Periodontology, vol. 70, no. 12, (1999), pp. 1523-1539.

[7] D. Buser, R. K. Schenk, S. Steinemann, J. P. Fiorellini, C. H. Fox and H. Stich, "Influence of surface characteristics on bone integration of titanium implants", A histomorphometric study in miniature pigs, vol. 25, no. 7, (1991), pp. 889-902.

[8] C. Larsson, P. Thomsen, B. O. Aronsson, M. Rodahl, J. Lausmaa, B. Kasemo and L. E. Ericson, "Bone response to surface-modified titanium implants: studies on the early tissue response to machined and electropolished implants with different oxide thicknesses", Biomaterials, vol. 17, no. 6, (1996), pp. 605-616.

[9] K. J. Lee, M. P. Neupane, B. Yu, I. S. Park, M. H. Lee and T. S. Bae, "Surface Characteristics of Titanium Implant Modified by Blasting and Acid-Etching Treatment", Graduate School, Chonbuk National University, (2008).

[10] R. M. Doh, H. S. Moon, J. S. Shim and K. W. Lee, "Retrospective study of the Implantium ${ }^{\circledR}$ implant with a SLA surface an internal connection with microthreads", J Korean Acad Prosthodont, vol. 47, no. 2, (2009), pp. 136-147.

[11] Wikipedia, "Thermal expansion coefficients of the elements [Internet]", Avalilable from: http://en.wikipedia.org/wiki/Thermal_expansion_coefficients_of_the_elements_(data_page).

[12] Korea Food \& Drug Administration, [Internet], Apr]http://www.mfds.go.kr/index.do? Mid $=675 \& \mathrm{seq}=14857 \& \mathrm{cmd}=\mathrm{v},(\mathbf{2 0 1 1})$.

[13] S. C. Park, I. H. Jeong and J. H. Kang, "The Study of Compression Shear Load of Implanting in Four Different Fastening Method”, International Journal of Bio-Science and Bio-Technology, vol. 7, no. 2, (2015), pp.

[14] M. R. Norton, "In vitro evaluation of the strength of the conical implant-to-abutment joint in two commercially available implant systems", J Prosthetic Dent, vol. 83, no. 5, (2000), pp. 567-571.

[15] S. C. Park, H. S. Kim and S. W. Ham, "A Study on the Screw Loosening Torque According to the Type of Tightening the Implant Fixture and Abutment", J Korean Acad dental Technology, vol. 35, no. 3, (2013), pp. 201-207.

[16] T. G. Eom, S. W. Suh, G. R. Jeon, J. W. Shin and C. M. Jeong, "Effect of Tightening Torque on Abutment-Fixture Joint Stability using 3-Dimensional Finite Element Analysis", J Korean Acad Prosthodont, vol. 47, no. 2, (2009), pp. 125-135.

[17] O. Jamiyandorj, J. H. Kim, M. S. Kim, Y. B. Park and J. S. Shim, "Comparison of removal torque between prefabricated and customized abutment screw", J Korean Acad Prosthodont, vol. 50, no. 4, (2012), pp. 243-248.

[18] K. B. May, M. J. Edge, M. M. Russell,M. E. Razzoog and B. R. Lang, "The precision of fit at the implant prosthodontic interface”, The Journal of Prosthetic Dentistry, vol. 77, no. 5, (1997), pp. 497-502.

[19] J. Y. K. Kan, K. Rungcharassaeng, K. Bohsali, C. J. Goodacre and B. R. Lang, “Clinical methods for evaluating implant framework fit", The Journal of Prosthetic Dentistry, vol. 81, no. 1, (1999), pp. 7-13.

[20] S. C. Park, C. S. Kim and I. H. Jeong, "Research on Precision by Upper Diameter of Implant Fixtures", Advanced Science and Technology Letters, vol. 91, (2015), pp. 1-6.

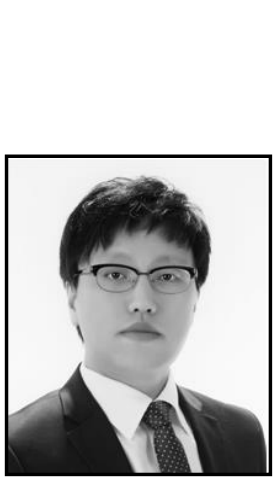

\section{Authors}

\section{Soo-chul Park}

22 Feb. 2012 : Ph.D. degree at Yeungnam University, Korea

1 Mar. 2013 recent: assistant professor, Department of Dental Technology Gimcheon University, Korea

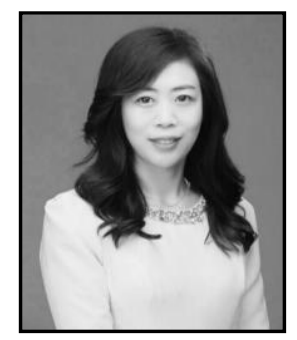

\section{Chang-Suk Kim}

22 Feb. 2013 : Ph.D. degree at Yeungnam University, Korea

1 Mar. 2010 recent: assistant professor, Department of Dental Hygiene, Ulsan College, Korea 


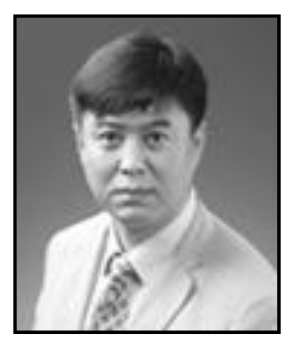

\section{In-Ho Jeong}

22 Feb. 2008 : Ph.D. degree at, Department of Public Health Graduate School Daegu Haany University, Korea

21 Mar. 2005 recent: assistant professor, Department of Dental Technology Gimcheon University, Korea 